\title{
PROFESSIONAL NURSES KNOWLEDGE AND UNDERSTANDING OF AIDS/HIV INFECTION
}

\author{
NJ CHAMANE and W KORTENBOUT
}

\section{ABSTRACT}

This study examined professional nurses' knowledge and understanding of AIDS/HIV infection.

The sample was formed by 53 professional nurses; 27 being those that have done the AIDS counselling course (trained counsellors) and 26 who have not done the course. This sample was randomly chosen from a population of 192 professional nurses representing all departments.

Questionnaires were sent to the participants and focus group interviews formed by a group of 21 participants, were done to elicit any information that may not have been obtained through the use of a questionnaire.

The results showed good knowledge of general information which included the mode of spread of infection. Lack of knowledge in identification of high risk groups, symptoms. diagnostic tests and use of universal precautions in specific areas was identified.

\section{INTRODUCTION}

The study focused on the specialised hospital professional nurses' knowledge and understanding of AIDS/HIV infection. The researchers' interest was triggered by the rate of HIV infection in the hospital where the study was done. This showed a rise in the number of HIV infected patients, from 89 in 1990 to 145 in 1992 , with the wards having an average of $30 \%$ of HIV infected patients.

The above picture related to HIV infection in the world which showed a tremendous growth since early eighties up to this juncture and this appears to be the problem for the country's health and economic system. The worlds' statistics (on HIV infected people) showed this pattern:- 1990 :$74000-102000,1991:-191926-201617,2000$ :- an estimation of 38-110 million HIV infected people.

(AIDS Bulletin; December 1992; vol 2,\& AIDS Training and Information Centre.1993.)

It is realised that the professional nurses had a big role to play in the prevention of spread of infection, whose actions would be based on knowledge and understanding of AIDS/HIV infoction.

\section{RESEARCH OBJECTIVES}

The main aim of the study was to explore the knowledge held by the professional nurses in a specialised hospital, about AIDS/HIV infection.

To estimate the number of AIDS/HIV infected patients, that the professional nurses had to deal with in each ward, so as that the intensity of exposure could be measured.

\section{THEORETICAL FRAMEWORK}

Two theories were combined to form a framework. These were:-

1. COGNITIVE DISSONANCE THEORY

2. FEAR OF CONTAGION THEORY

\section{COGNITIVE DISSONANCE}

This theory assumes that people want to maintain consistency in their beliefs, attitudes, values and behaviours. If individuals confront examples of their own inconsistency in these areas they will experience psychological discomfort and be motivated to eliminate the inconsistency. (Wicklund \& Brehim, 1976)

\section{FEAR OF CONTAGION}

This is an affective stress-response to illness Fear of Contagion is an anxious response to the perceived threat of catching the disease. Three behaviours characterise this kind of fear:avoidance, taking extreme precautions and verbal expression of fear regarding the disease. (Meisenhelder \& La Charite, 1989)

Both theories clearly indicated that individuals would try by all means to maintain equilibrium or eliminate dissonance by either by avoiding the situation that causes disequilibrium or engaging in behaviours that would be directed at reducing the inconsistency. Fear of Contagion was seen to be the result of cognitive dissonance, since it is a stress-coping response.

\section{LITERATURE RELATED TO THE STUDY}

Previous studies by Akisanya \& Rouse (1992) indicated that AIDS/HIV infection still appears as the most feared disease due to its incurability and its association with death and because of its prognosis. It was highlighted that fear would be worsened by lack of knowledge. Further support was from the study done in England in 1988 \& 1990 which explored knowledge and attitude and revealed that nurses with limited knowledge base had judgemental and negative attitudes towards AIDS/HIV infected patients. (Eysenick, 1992 ; Akisanya \& Rouse 1992)

A study done in 1991 on nursing, psychology and design students to evaluate the relationship between knowledge, attitude and the rate of contact with HIV infected patients, showed no relationship between knowledge and attitude but a strong relationship between rate/degree of contact and attitude. That is then the reason for inclusion of the rate of infection in each ward, which would influence the degree of contact and exposure to HIV infected patients in this study. (Robbins et.al 1992)

Bond et.al (1990) did a survey on experience and knowledge of community nursing staff in England and found that nurses lacked confidence in doing tasks and procedures for AIDS/HIV infected patients which included providing health education, counselling and rendering terminal care. This was related to lack of experience since most of them had less contact with HIV infected patients and as a result presented with fear. (Bond et.al, 1990; Akisanya \& Rouse, 1992)

\section{METHODOLOGY}

This was a descriptive survey whereby questionnaires and focus group interviews were used. Questionnaires were used to collect data and in addition, focus group interviews were used to elicit information that could not be obtained through the use of a questionnaire.

\section{SAMPLE AND SAMPLING METHOD}

A sample of 60 professional nurses was drawn from a total of 192 professional nurses working in various wards/departments in a specialised hospital. Fifty percent was formed by Trained AIDS counsellors (30) and 50\% was randomly selected from the rest of the professional nurses that have not done the AIDS counselling course, but work in the same setting.

Both verbal and written informed consents were obtained from the participants. These included the pilot study, focus group and questionnaire participants respectively. In the letter seeking permission, the participants' rights were 
explained including voluntary participation. The purpose of the study was explained. Confidentiality was assured. Participation was outside working time. Prior to conducting the study, permission was obtained from the Medical Superintendent, Chief Nursing Service Manager and Natal Provincial Administration.

\section{CONTROLLING BIAS AND CONTAMINATION OF THE STUDY}

The content was valid in a sense that bias was limited. The pilot study was done to check if the questionnaire was clear and to ensure correct timing of participants. To avoid contamination of the main study, the pilot study participants were not included in the main study. The same applied to focus group interview participants. Both groups were selected after sampling for the selection of questionnaire participants.

\section{CONTENT VALIDITY}

The tool content was valid in a sense that it was based on the literature studied, (Eusenick, 1992; Meisehelder \& La Charite, 1989) and the theoretical framework. The questions were phrased in such a way that could elicit behaviours characterising both theories, as well as actual knowledge and understanding of the disease/infection.

There were open- and close-ended questions . The yes/no questions had options like "other", and the respondent had to specify the other altemative. The same applies to the agree/disagree questions which had the option of stating if "unsure/undecided". All answers were grouped, analysed and interpreted accordingly.

\section{DATA ANALYSIS AND \\ INTERPRETATION}

\section{Knowledge and Understanding in Relation to Attitude}

Although this study showed good general knowledge, there was a limited knowledge base of specific information like prevention of spread of infection, use of protective clothing and the diagnostic tests available. As a result $22 \%$ respondents showed a negative attitude to HIV infected patients. When this question was counterchecked, the negative attitude increased to $43 \%$ when including those that were undecided.

\section{Rate of Contact (Experience) and Attitude}

The study revealed that almost all (95\%) wards had HIV infected patients which increased the chances of contact and experience. This was looked upon as the reason for the $78 \%$ positive attitude that initially showed in the first question that assessed attitude. The positive attitude was further shown by the focus group respondents who felt that if they could refuse to care, who then should care. This then showed a strong relationship between experience/degree of contact and attitude.

\section{Risk of Infection when Nursing HIV} Infected Patients

It was surprising to discover that some questionnaire respondents were not truthful in answering the fear question. This was discovered when they were asked to indicate the perceived risk of getting infection when nursing HIV infected patients. The results showed that $31 \%$ perceived the risk as low (less fearful), which is the actual occupational risk according to the literature (Moss,1992). The rest, 69\% perceived the risk as moderate to high. This tied up with the focus group participants who perceived the risk as high and expressed fear for infected patients. See Figure 3 below:-

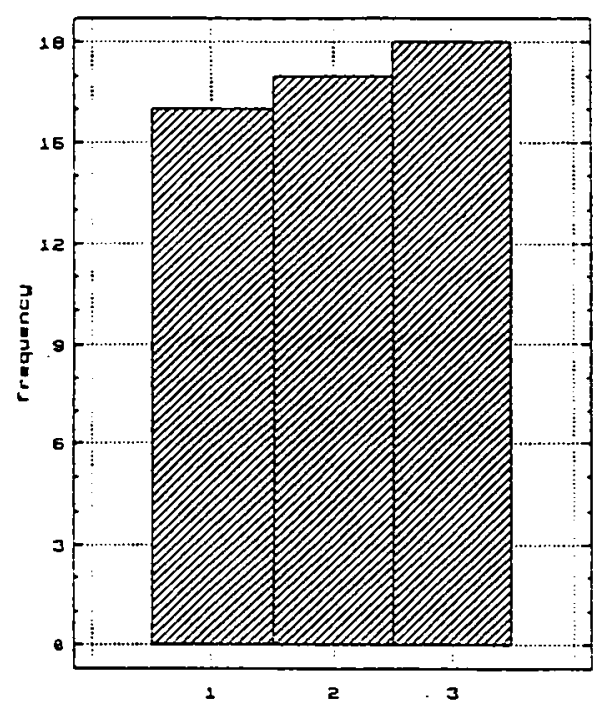
patients, and 69\% expressed no fear. It is
believed that this is related to lack of knowledge as mentioned by the focus group participants. See Figure. 2 below.

\section{Knowledge and Fear}

Out of 49 responses to a fear question, $31 \%$ respondents expressed fear of HIV infected patients, and $69 \%$ expressed no fear. It is
believed that this is related to lack of knowledge

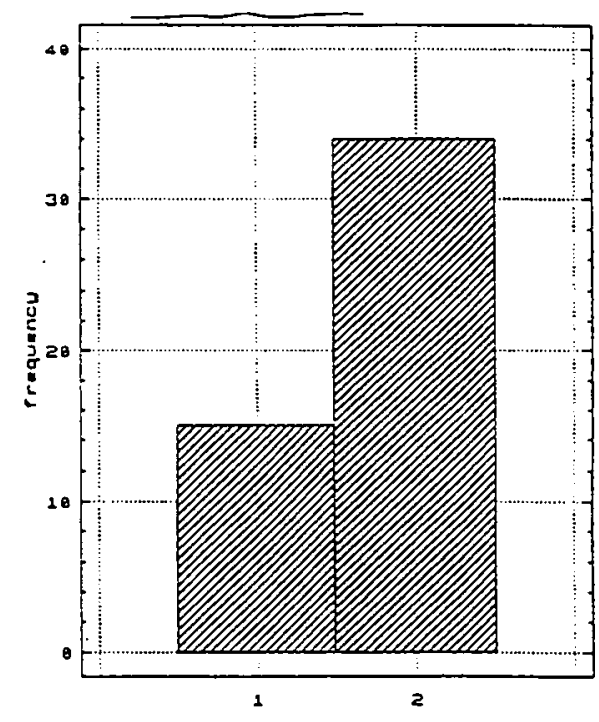

FIGURE 2. KNOWLEDGE AND FEAR

Key $1=$ fear, 2 = no fear

\section{FIGURE.3 PERCEIVED RISK OF GETTING INFECTION}

Key:- 1 =very low; 2 = moderate; $3=$ very high

\section{Knowledge and Beliefs}

There was a section exploring beliefs about the use of condoms, or vaginal douche after sexual intercourse to reduce the risk of getting infection. Almost all respondents (96\%), believed that vaginal douche after sexual intercourse could not reduce the risk of getting infection but use of condoms could reduce the risk; $83 \%$ of nurses knew that one antibody test could not conclusively establish sero-negativity; and $87 \%$ believed that the general appearance could not provide evidence of HIV infection. The same applied to focus group respondents who believed that general physical appearance could not tell if a person is sero-positive, but with the antibody test the majority of focus group respondents did not know about the window period.

\section{Lack of Knowledge in Universal Precautions}

This was mainly marked in a section that dealt with use of universal precautionslprotective clothing to prevent spreadlcontamination of 
infection. Both groups were equally unsure with this aspect. The participants were using conflicting protective clothing for similar situations, which was a sign of uncertainty.

\section{Knowledge Difference Between Two Groups}

It was discovered that the Trained AIDS counsellors had better knowledge than the professional nurses who had not done the course. But when the differences were tested statistically, no statistical difference was noted except on knowledge of diagnostic tests whereby the Trained counsellors had better knowledge, both numerically and statistically. See diagram below, which showed the numerical difference.

\section{CONCLUSIONS AND RECOMMENDATIONS}

\section{KNOWLEDGE AND UNDERSTANDING}

The general knowledge of all the professional nurses was found to be fairly high. This included knowledge of causes, predisposing factors and mode of spread. Limited knowledge was noted in specific areas like identification of highly infections body fluids, tests available to detect HIV infection of opportunistic infections. Uncertainty was seen in the use of universal precautions (protective clothing) which forms the major aspect in preventing the spread of infection in the working environment.

\section{FEAR OF CONTAGION AND COGNITIVE DISSONANCE}

The sudy revealed marked fear of contracting the disease irrespective of the knowledge pattern and experience. This was aggravated by the fact that the disease is incurable at this juncture. The focus group revealed the fact that the highly perceived fear is that of "knowing" that one has got HIV infection; and the participants felt that people do not die of AIDS and its complications per se but die more of "knowing" and the depression associated with this incurable monster which further lowers their immunity. It was discovered that those were the reasons for taking extreme precautions, avoidance of challenging situations and verbalisation of fear.

The nurses felt that they needed to be comfortable with themselves so as to be able to care for other individuals, but found this to be a problem with HIV infection since they lacked knowledge especially those that have not done the counselling course. As far as universal precautions are concerned, both groups were uncomfortable, as indicated by the analysis of the focus group discussions.

\section{ATTITUDE}

Although $66 \%$ of participants showed positive attitude, the rest showed a negative attitude. This was expressed in questionnaire results when people expressed the feeling that when given the chance, they would refuse to care for HIV infected patients and preferred that care be rendered on voluntary basis. The group with a positive attitude felt that if they were to refuse to render such care, who than should care for these people!

\section{RECOMMENDATIONS}

\section{Aids Counselling Course}

This programme increases awareness and knowledge base for professional nurse and would enable them to cope with challenges associated with HIV infection.

\section{Universal Precautions}

It is recommended that this portion be included in the counselling course as a preventive measure which is also recommended by Centre for Disease Control (CDC). This should add on the hospital infection control policies that act as guidelines for prevention of infection.

\section{Curriculum for Basic Training}

The nurse should have communication skills, so as to be able to fulfill roles of counsellor, health educator, referral agent and patient advocate. It is then recommended that counselling lessons should be included in the curriculum for all health team members so as to improve on these skills that are needed in the health sector. This was further supported by Sminoff et.al (1990).

\section{Aids Education Programme}

Although this has started, more emphasis should be on prevention of spread which showed as a knowledge gap in this study and in previous studies (Akisanya and Rouse, 1992). Recommended are not only the educational programmes, but evaluation of materials used in such programmes as to ensure their effectiveness and appropriateness. Special programmes should also be directed to specific areas like fear reduction, anxiety, attitudinal change, and psychological care.

\section{Aids Consultants/Specialists}

This is a recommendation for the entire profession which should develop such people, who would have in depth knowledge and understanding pertaining the disease and should be continuously researching on this field so as keep the profession up to date with the information and various changes. This was suggested by the focus group participants who identified a need for the consultants.

\section{Areas of Further Research}

1. Perception of nursing staff re-confidentiality in AIDS management.

2. Traditional-healers and AIDS (knowledge, beliefs, attitudes and prevention).

3. Strategies to allay fears and dissonance reAIDS/HIV infection.

4. Evaluation of AIDS education programmes.

\section{REFERENCES}

AIDS Training And Information Centre (ATIC) (1993). Personal Communication 31.01.93. Durban.

Akisanya, J.A.,\& Rouse, P.(1992). Who will care? A survey of knowledge and attitude of hospital nurses to people with AIDS/HIV. Loumal of Advanced viursing. $17,400-401$.

Bond,S, Rhodes,T, Philips,P., Setters,J, Foy,C.\& Bond J (1990). HIV infection and AIDS in England: The experience, knowledge and intentions of community nursing staff. Joumal of Advanced Nursing 15, 249-255.

KEY:-

$0=$ WRONG $N$ NO ANSWER $1=$ ELSA

$2=$ IFA $3=$ WESTERN BLOT 
Burns, N., \& Groove, S.K.,(1987). The Practice of Nursing Research. Critique and Utilisation. London: W.B.Saunders.

Centre for Disease Control (1989). Guidelines for prevention of transmission of Human Immunodeficiency Vinus and Hepatitis B Virus to health care and public-safety workers. Mortidity and Monality weekly repon 38 (6).

Eysenck, M.W.,(1992). ANXIETY. The Cognitive Perspective. United Kingdom: Sage Publications.

Meisenhelder, J.B., \& LaCharite, C.L., (1989). Fear of Contagion: A stress-response to acquired
Immunodeficiency syndrome. Adyances in Nursing Science, 11(2), 29-37.

Siminoff, L.A., Erlen, J.A., \& Lidz, C.W.(1990). Stigma, AIDS and quality of nursing care: State of science. Joumal of Advanced Nursing Science. 16 262-269.

Stewart, D.W.,(1990). Eocus Group Theory and Practice : Applied Social Research Methods Series. Newbury Park: Sage Publications.

Wicklund, R.A., \& Brehim, J.W. (1976). Perspectives of Cognitive Dissonance New York: Lawrence Eribaum Associate Publishers.
Nomusa Joyce CHAMANE Masters in Nursing Science (M.CUR)

W KORTENBOUT Ph.D accepted for publication while Senior Lecturer Department of Nursing UNIVERSITY OF NATAL 